
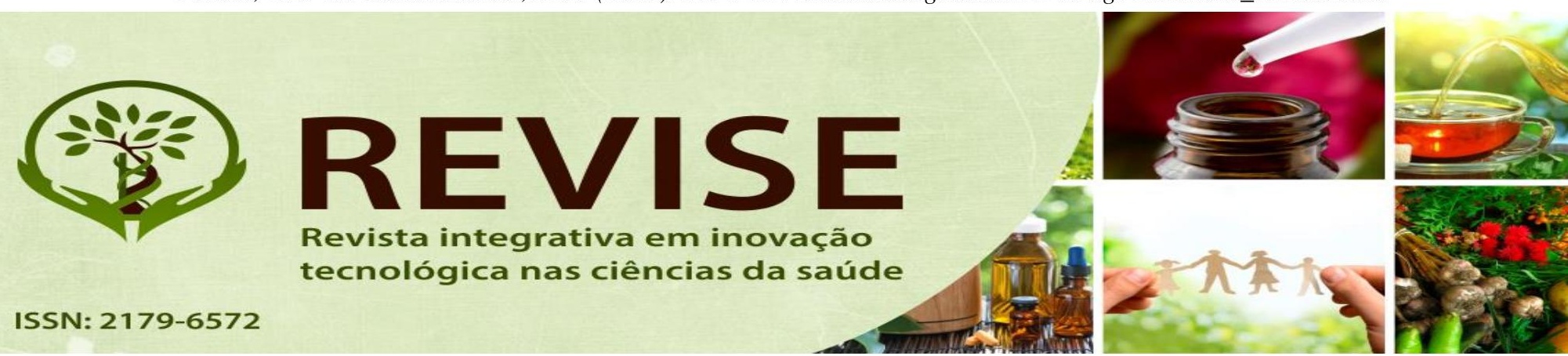

ISSN: 2179-6572

Revista integrativa em inovação tecnológica nas ciências da saúde

\title{
DESAFIOS À PRÁTICA DO ACOLHIMENTO NA ATENÇÃO PRIMÁRIA EM SAÚDE NO BRASIL
}

\author{
Caroline Santos Passos \\ UNIT \\ Bárbara Eduarda Panelli-Martins \\ $U F R B$
}

\begin{abstract}
Resumo
As políticas públicas adotadas pelo SUS têm passado por sucessivas mudanças, em busca de ratificar a saúde como direito universal. $\mathrm{O}$ acolhimento, diretriz operacional da Política Nacional de Humanização (PNH) da Atenção e Gestão do SUS (Humaniza SUS), vem ganhando diretriz própria e relevância na atenção primária à saúde (APS) para garantir acesso humanizado e resolubilidade às demandas de saúde dos usuários no Brasil. Realizou-se uma revisão integrativa de literatura sobre os desafios para realização do acolhimento na operacionalização e qualificação do SUS na Atenção Primária à Saúde - APS. A base de dados consultada foi a Scientific Electronic Library Online (SciELO). Os resultados apontaram que as principais dificuldades relacionadas ao acolhimento foram: relacionamento entre profissionais e usuários, sobrecarga de trabalho dos profissionais de saúde, ausência de espaço adequado para reorganizar o processo de trabalho as filas de espera. Tais fatores fragilizam a proposta do acolhimento e coloca em risco a longitudinalidade no cuidado para os usuários da APS no Brasil.
\end{abstract}

Palavras-Chave: Atenção Primária em saúde. Estratégia Saúde da Família. Acolhimento.

\section{Abstract}

The public policies adopted by SUS (the Brazilian Unified Health System) have undergone successive changes, to ratify health as a universal right. Receptivity, an operational line of the National Humanization Policy (PNH) of SUS Care and Management (Humaniza SUS), has been gaining its own guideline and relevance in primary health care (PHC) to guarantee humanized access and resolubility to users' health demands in Brazil. An integrative literature review on the challenges to accomplish receptivity of the host in the operationalization and qualification of SUS in Primary Health Care- PHC supported by the Scientific Electronic Library Online (SciELO) database was performed. The results pointed out that main difficulties related to the reception were: relationship between professionals and users, workload of health professionals, lack of adequate space to reorganize the work process with waiting lines. These factors weaken theuser receptivity proposal and jeopardize longitudinality in care for PHC users in Brazil.

Key Words: Primary Health Care Attention. Family Health Strategy. User receptivity.

Acolhimento. Revista Revise, vol 3, Dossiê Gestão em Saúde, p.56-70. 

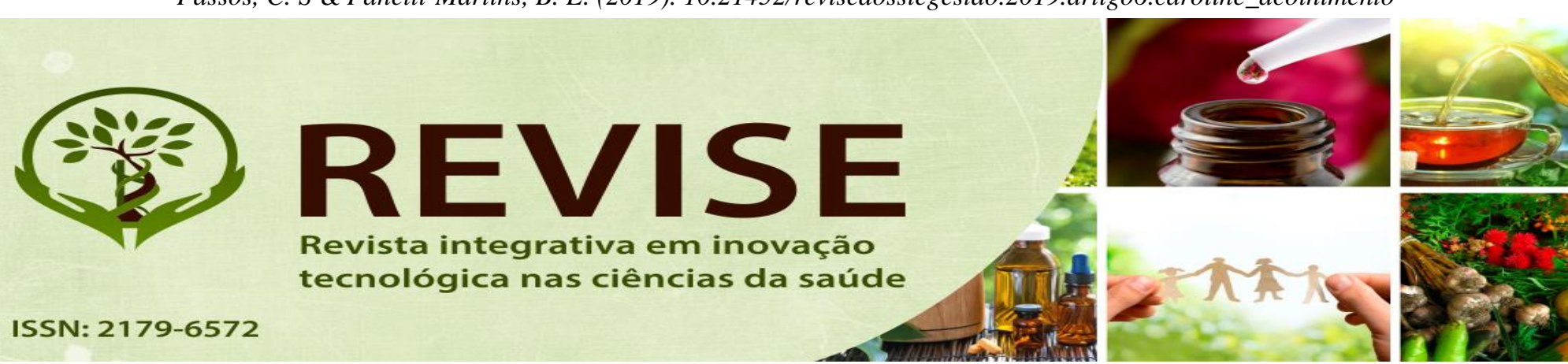

ISSN: 2179-6572

Revista integrativa em inovação tecnológica nas ciências da saúde

\section{Introdução}

A Organização Mundial da Saúde (OMS) define saúde como "completo bem estar físico mental e social, não somente a ausência de doenças”. A Constituição Federal (CF) de 1988, no Art. 196 reconhece a saúde como "direito de todos e dever do Estado, garantido mediante políticas sociais e econômicas que visem à redução do risco de doença e de outros agravos e ao acesso universal e igualitário às ações e serviços para sua promoção, proteção e recuperação".

O Sistema Único de Saúde (SUS) foi criado pela CF de 1988e regulamentado pela lei $\mathrm{n}^{\text {o }}$ 8.080/90 que o define como um conjunto de ações e serviços de saúde, prestados por órgãos e instituições públicas federais, estaduais e municipais, da Administração direta e indireta e das fundações mantidas pelo Poder Público, tendo como princípios a universalidade, integralidade e equidade. O desempenho do SUS está intimamente ligado ao acesso à APS. Sendo assim, a busca por uma rede de assistência em saúde que garanta tais princípios, dispõe de um conjunto de ações e estratégias com foco na otimização deste setor.

Um marco importante com relação aos cuidados primários em saúde surgiu com a Declaração de Alma Ata, em 1978 na qual a Atenção Primária à Saúde (APS) corresponde aos cuidados essenciais à saúde, baseados em tecnologias acessíveis, que levam os serviços de saúde o mais próximo possível dos lugares de vida e trabalho das pessoas, constituindo, assim, o primeiro nível de contato com o SUS, e o primeiro elemento de um processo contínuo de atenção. A APS funciona como porta de entrada do SUS, segundo Campos et al. (2014), sendo assim é ela quem ordena o trabalho dos demais níveis de atenção. No intuito de reorganizar o modelo da APS utilizado no Brasil foi criada em 1994 a Estratégia Saúde da Família (ESF) (SORATTO ET AL., 2015). A ESF é tida como estratégia de expansão, qualificação e consolidação do modelo de atenção por favorecer uma reorientação de processo

Acolhimento. Revista Revise, vol 3, Dossiê Gestão em Saúde, p.56-70. 

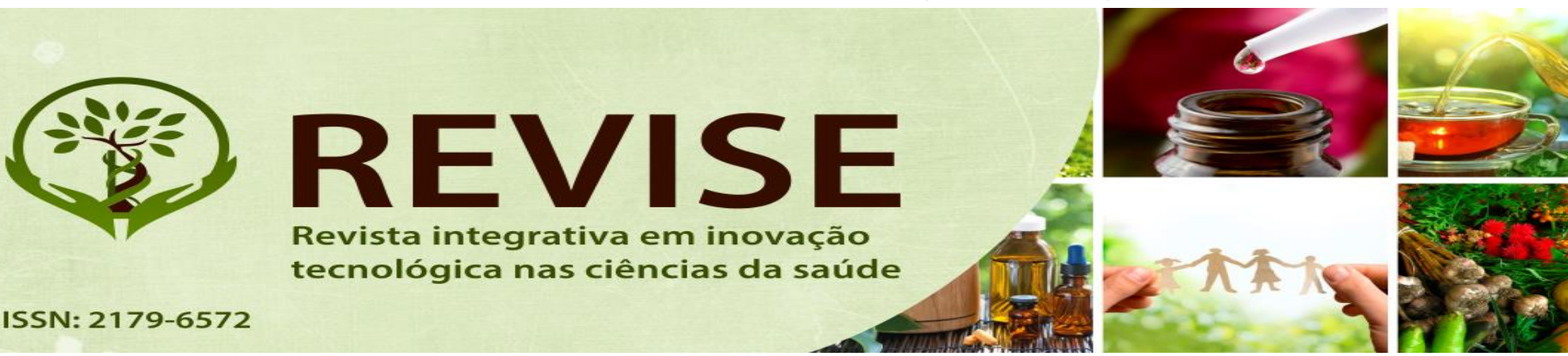

ISSN: $2179-6572$

Revista integrativa em inovação tecnológica nas ciências da saúde

de trabalho impactando na saúde das pessoas de forma individual e coletiva. Sendo assim, na ESF os profissionais precisam desenvolver processos de trabalho que estabeleçam uma relação entre si e a comunidade, efetivadas pelo desenvolvimento de ações humanizadas.

O Ministério da Saúde tem utilizado de estratégias como a implantação da Politica Nacional de Humanização (PNH), com o intuito de adequar os conhecimentos às novas orientações de estruturação da APS (COUTINHO, BARBIERI E SANTOS, 2015). A PNH HumanizaSUS foi criada em 2003 com o intuito de praticar os princípios do SUS no cotidiano da atenção e gestão em saúde pública no Brasil, qualificando e incentivando trocas solidárias e ações humanizadas entre usuários, trabalhadores e gestores, e vem ganhando diretriz própria e relevância na APS para garantir acesso humanizado e resolubilidade às demandas de saúde dos usuários. Dentre as diretrizes da PNH, está o acolhimento (BRASIL, 2010).

Sem a realização do acolhimento é impossível realizar um atendimento de qualidade, assim, a ESF o constitui como base para o seu processo de trabalho. Um dos parâmetros para acompanhamento da implementação da PNH, segundo o Ministério da Saúde, são as diversas formas como o acolhimento é realizado; inclusão do usuário de forma que promova a otimização dos serviços, o fim das filas de espera, a hierarquização de riscos e o acesso aos demais níveis de assistência (BRASIL, 2010).

O acolhimento, para Tedesco e Junges (2013), se baseia no estabelecimento de relações solidárias e de confiança entre os profissionais e usuários que buscam os serviços, para resolver seu problema de saúde, tornando-se aspecto importante para que ocorra o vínculo, contribuindo para a resolução do problema. É definido em documentos oficiais segundo Garuzi et al. (2014), como a recepção do usuário no serviço de saúde, compreende a responsabilização dos profissionais pelo usuário, a escuta qualificada de sua queixa e angústias, a inserção de limites, se for preciso, a garantia de assistência resolutiva e a articulação com outros serviços para continuidade do cuidado quando necessário.

$\mathrm{O}$ acolhimento no campo da saúde, de acordo com a PNH, se refere à construção de interações interpessoais baseadas em uma escuta atenta, eticamente comprometida e

Acolhimento. Revista Revise, vol 3, Dossiê Gestão em Saúde, p.56-70. 

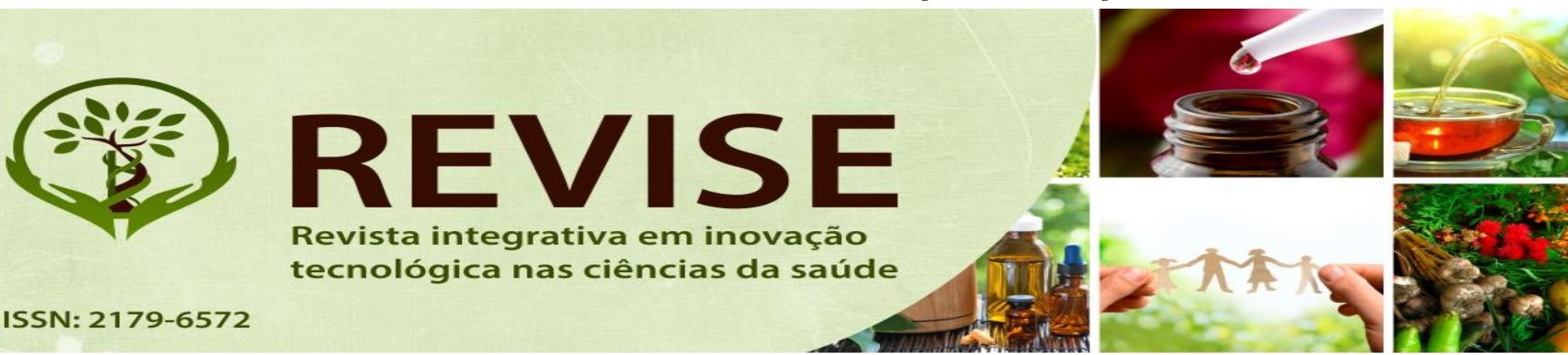

ISSN: $2179-6572$

Revista integrativa em inovação tecnológica nas ciências da saúde

interessada no reconhecimento do outro, desta forma, não deve ser restrito a um setor do serviço composto por determinados profissionais a serem escalados para receber as pessoas em busca de cuidado. Seu conceito se relaciona a atitude, a uma postura ética a ser adotada por todos os envolvidos no trabalho (SATO E AYRES, 2015). Diante deste contexto que o estudo apresenta como objetivo identificar e analisar os principais desafios para a realização do acolhimento na APS no âmbito da ESF.

\section{Método}

Trata-se de pesquisa bibliográfica, exploratória e descritiva desenvolvida por meio de uma revisão integrativa de literatura. Visando atingir o objetivo proposto, foram seguidas as seguintes etapas da revisão integrativa: “(1) elaboração da questão norteadora; (2) busca ou amostragem na literatura; (3) coleta de dados; (4) análise crítica dos estudos incluídos; (5) discussão/interpretação dos resultados; e (6) apresentação da revisão.” (SOUZA, SILVA E CARVALHO, 2010).

Foi estabelecida a seguinte questão norteadora: quais são os principais desafios encontrados no acolhimento na APS no Brasil?

A base de dados utilizada foi a Scientific Electronic Library Online (SciELO), para a busca de artigos utilizando-se os seguintes descritores de forma isolada ou combinada nos idiomas português, inglês e espanhol: Atenção Primária/Primary Attention/Atención Primaria; Estratégia Saúde da Família/Family Health Strategy/Estrategia Salud de la Familia; Acolhimento/User embracement/ Acogidadel usuario.

Como critérios de inclusão, adotou-se: textos completos, com acesso livre na base de dados, nos idiomas português, inglês e espanhol, publicados entre 2013 e 2017, que tratam de acolhimento na APS no Brasil.

Foram excluídas pesquisas que tratavam de programas ou práticas de categorias profissionais específicas; artigos em duplicidade; estudos que não abordavam a temática relevante ao alcance do objetivo da revisão. 

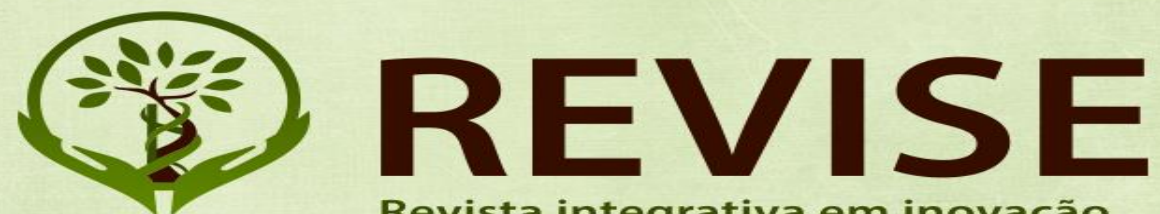

Revista integrativa em inovação tecnológica nas ciências da saúde

ISSN: 2179-6572
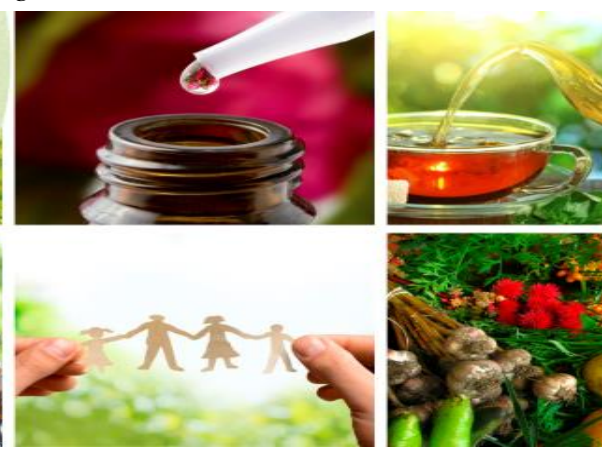

A busca retornou com 30 (trinta) artigos, decorrendo-se a seleção dos mesmos por meio da leitura dos títulos e resumos analisando a contribuição ao assunto abordado. Após aplicação destes critérios, 05 (cinco) artigos foram analisados.

\section{Resultados e Discussão}

A busca resultou em 30 (trinta) artigos e, a partir da leitura dos resumos, foram selecionados 05 (cinco) artigos que atendiam ao objetivo proposto. Quanto ao tipo de estudo, 04 (quatro) eram de natureza qualitativa (80\%) e 01 (um) de caráter quantitativo (20\%). Após análise crítica e sistematização dos dados, foram evidenciadas 04 (quatro) diretrizes principais para discussão: Relação profissional-usuário; Sobrecarga de trabalho; Ambiência; Morosidade no Atendimento.

Quadro 1- Descrição dos artigos localizados na base de dados 

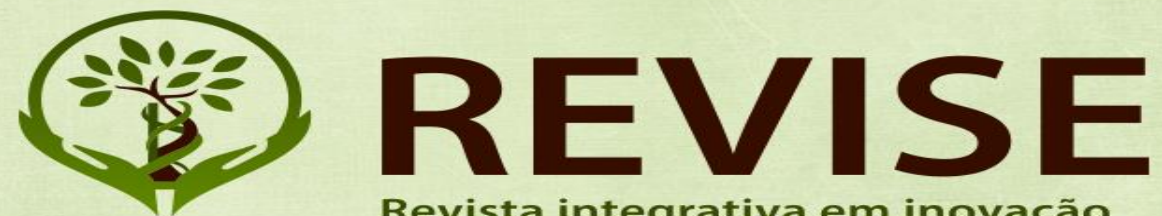

Revista integrativa em inovação tecnológica nas ciências da saúde
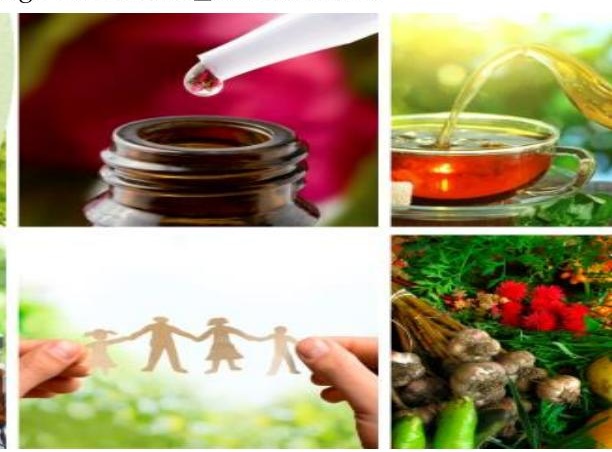

\begin{tabular}{|c|c|c|c|}
\hline Título do Artigo & Autores & Resultados & $\begin{array}{l}\text { Recomendações } \\
\text { Conclusões }\end{array}$ \\
\hline $\begin{array}{l}\text { 1. Acolhime } \\
\text { nto na } \\
\text { Atenção } \\
\text { Primária } \\
\text { à Saúde: } \\
\text { revisão } \\
\text { integrativ } \\
\text { a }\end{array}$ & $\begin{array}{l}\text { COUTINHO, L. R. } \\
\text { P.; BARBIERI, A. } \\
\text { R.; SANTOS, M. L. } \\
\text { M. } 2015\end{array}$ & $\begin{array}{l}\text { O acolhimento ainda } \\
\text { não está totalmente } \\
\text { sistematizado nos } \\
\text { modelos de atenção à } \\
\text { saúde, e esta questão } \\
\text { pode justificar as } \\
\text { dificuldades } \\
\text { apresentadas pelos } \\
\text { profissionais a } \\
\text { usuários. }\end{array}$ & $\begin{array}{l}\text { Estudos com novas } \\
\text { abordagens ou } \\
\text { estratégias para a } \\
\text { sistematização do } \\
\text { acolhimento, além de } \\
\text { verificar se estas têm } \\
\text { impacto real na } \\
\text { qualidade dos } \\
\text { serviços e na } \\
\text { satisfação dos } \\
\text { usuários. }\end{array}$ \\
\hline $\begin{array}{l}\text { 2. Acolhimento } \\
\text { na visão } \\
\text { complexa: ação } \\
\text { coletiva } \\
\text { emergente na } \\
\text { Equipe de } \\
\text { Saúde da } \\
\text { Família }\end{array}$ & $\begin{array}{l}\text { ROCHA, S. A.; } \\
\text { SPAGNUOLO, R. S. } \\
2015\end{array}$ & $\begin{array}{l}\text { Apresenta-se } \\
\text { fragmentado, } \\
\text { mediado pela } \\
\text { hierarquização das } \\
\text { relações de poder, } \\
\text { atravessador por } \\
\text { regras rígidas e forte } \\
\text { apego ao controle, } \\
\text { que dificultam a } \\
\text { evolução desse } \\
\text { sistema, que } \\
\text { profissionais } \\
\text { ultrapassem } \\
\text { exercício simples da } \\
\text { empatia em direção à } \\
\text { alteridade inerente } \\
\text { ao acolhimento. }\end{array}$ & $\begin{array}{l}\text { As relações gestores, } \\
\text { comunidade, } \\
\text { profissionais devem } \\
\text { ser potencializadas e } \\
\text { autor referenciadas } \\
\text { por conceitos claros } \\
\text { e inovadores } \\
\text { fundamentados em } \\
\text { um novo paradigma } \\
\text { da ciência que } \\
\text { permitam repensar as } \\
\text { práticas do } \\
\text { acolhimento } \\
\text { emergentes nos } \\
\text { pontos de encontro } \\
\text { da rede } \\
\text { tecnoassistencial } \\
\text { oferecendo subsí- } \\
\text { dios para evolução } \\
\text { desse sistema. }\end{array}$ \\
\hline
\end{tabular}

Acolhimento. Revista Revise, vol 3, Dossiê Gestão em Saúde, p.56-70. 

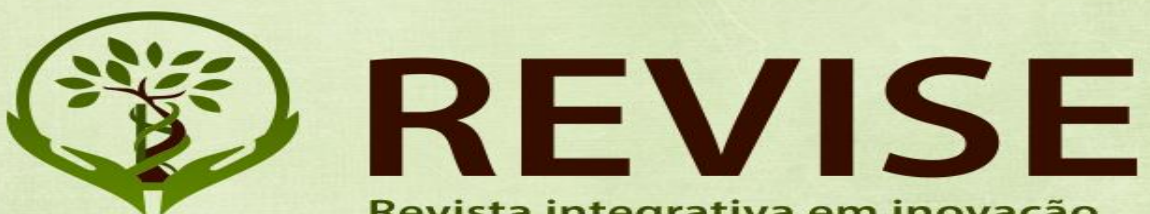

Revista integrativa em inovação tecnológica nas ciências da saúde

ISSN: 2179-6572
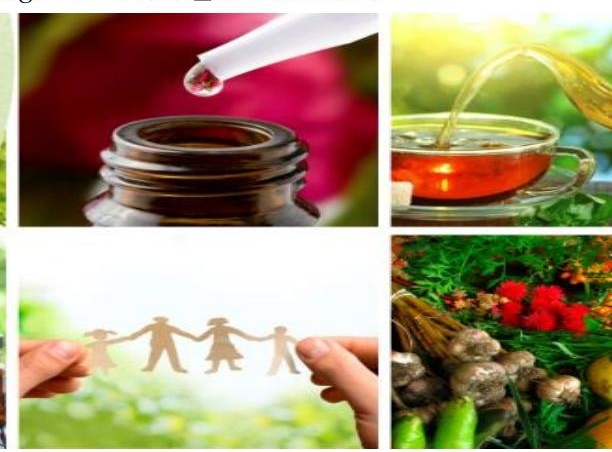

Fonte: elaborado pelas autoras

Relação entre profissionais e usuários

\begin{tabular}{|c|c|c|c|}
\hline $\begin{array}{l}\text { 3. Sobre o } \\
\text { acolhimento: } \\
\text { discurso e prática } \\
\text { em Unidades } \\
\text { Básicas de Saúde } \\
\text { do município do } \\
\text { Rio de Janeiro }\end{array}$ & $\begin{array}{llr}\text { SILVA, } & \text { T. } & \text { F.; } \\
\text { ROMANO, } & \text { V. } & \text { F. } \\
2015 & & \end{array}$ & 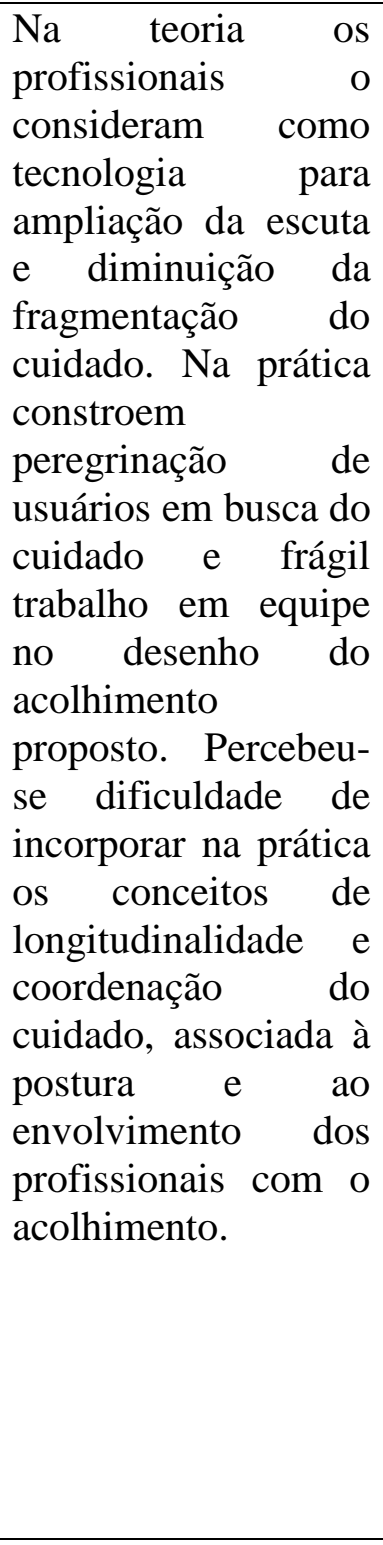 & $\begin{array}{l}\text { Destaque foi dado ao } \\
\text { apoio institucional } \\
\text { nesse processo. O } \\
\text { envolvimento e a } \\
\text { aproximação da } \\
\text { gerência com as } \\
\text { questões apontadas, } \\
\text { reuniões específicas } \\
\text { com o corpo técnico } \\
\text { das unidades, } \\
\text { reuniões periódicas } \\
\text { com os ACS, } \\
\text { participação nas } \\
\text { reuniões de equipe e } \\
\text { abertura de espaços } \\
\text { de discussão nas } \\
\text { reuniões gerais são } \\
\text { estratégias que } \\
\text { poderiam contribuir } \\
\text { para identificação de } \\
\text { prioridades e } \\
\text { corresponsabilização } \\
\text { dos profissionais, já } \\
\text { que no dito, o } \\
\text { acolhimento foi visto } \\
\text { como dispositivo } \\
\text { capaz de contribuir } \\
\text { para reorganização } \\
\text { do processo de } \\
\text { trabalho e } \\
\text { reconstrução de } \\
\text { práticas. }\end{array}$ \\
\hline
\end{tabular}

Uma boa relação entre profissional-usuário é um fator essencial para a concretização de um atendimento humanizado. Neste sentido, a ESF tem o intuito de humanizar as práticas

Acolhimento. Revista Revise, vol 3, Dossiê Gestão em Saúde, p.56-70. 

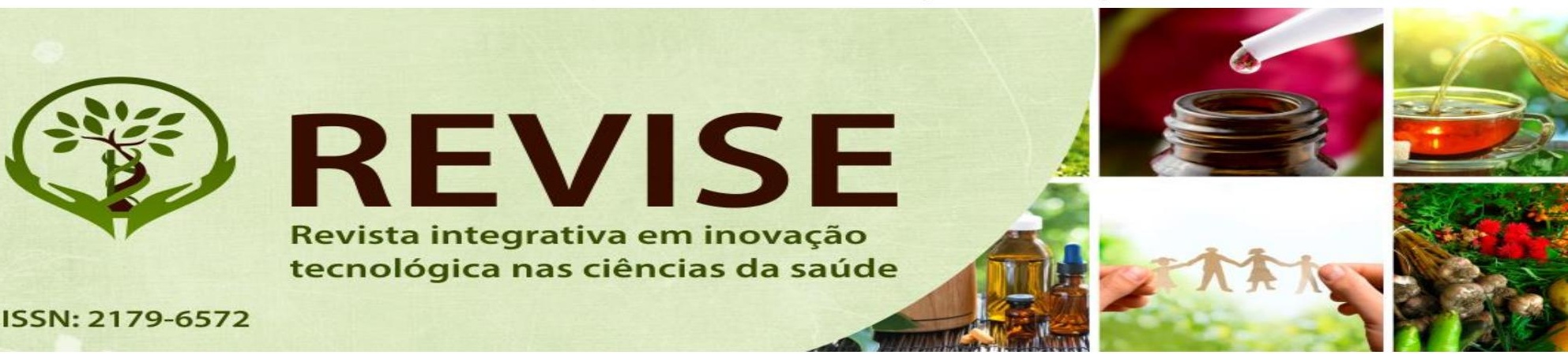

ISSN: 2179-6572

Revista integrativa em inovação tecnológica nas ciências da saúde

de saúde promovendo um relacionamento mais próximo dos profissionais com a comunidade, buscando a integralidade da assistência e o desenvolvimento de vínculo com a população, como proposto, possibilitando a longitudinalidade do cuidado (GIOVANI, 2013). Em seu estudo, Farias (2017) afirma que o trabalho na ESF, requer do profissional o conhecimento do significado de humanização. Uma postura acolhedora que envolve ética, escuta e compromisso em responder às necessidades de saúde trazidas pelo usuário são essenciais para a construção de um SUS humanizado (BRASIL, 2004).

Foram discutidos nos estudos aspectos referentes à relação entre os profissionais e usuários dos serviços de saúde na APS. A maioria dos estudos analisados (80\%) aborda claramente a questão, demonstrando existir dificuldades nesse sentido.

O estudo de Coutinho, Barbieri e Santos (2015) destaca como entraves no acolhimento a relação profissionais-usuários dos serviços, questões éticas destacando: falta de privacidade e sigilo nas interações entre profissional e usuário, de postura de escuta e comprometimento, de comunicação e de impessoalidade na relação, além da dificuldade de acesso a atendimento especializado e falta de respeito e despreparo dos profissionais.

Mitre et al. (2012 apud Tesser e Normam, 2014, p. 873) destacam que a proposta do acolhimento é a ampliação do acesso e promoção da melhoria na qualidade na relação entre os profissionais e usuários. Tesser et al. (2010 apud Tesser e Normam, 2014, p. 873) enfatizam que além de facilitar o acesso deve-se haver o resgate ético da melhoria dessa relação, transparecendo a fragilidade nesta questão. Os autores ressaltam ainda o caráter transversal do acolhimento, de natureza abrangente e uma proposta com base no "interesse pelo outro, numa postura ética de cuidado e numa abertura humana, empática e respeitosa ao usuário" (TESSER E NORMAM, 2014, p.873). Nesse sentido, destaca também que o contato não programado passa a ocorrer (ou deveria ocorrer) diretamente com a equipe de saúde e requer uma prática profissional com importante grau de comunicação, interpretação, negociação e responsabilidades compartilhadas, estimulando o vínculo, acalmando as ansiedades e buscando resoluções contextualizadas para os problemas. 

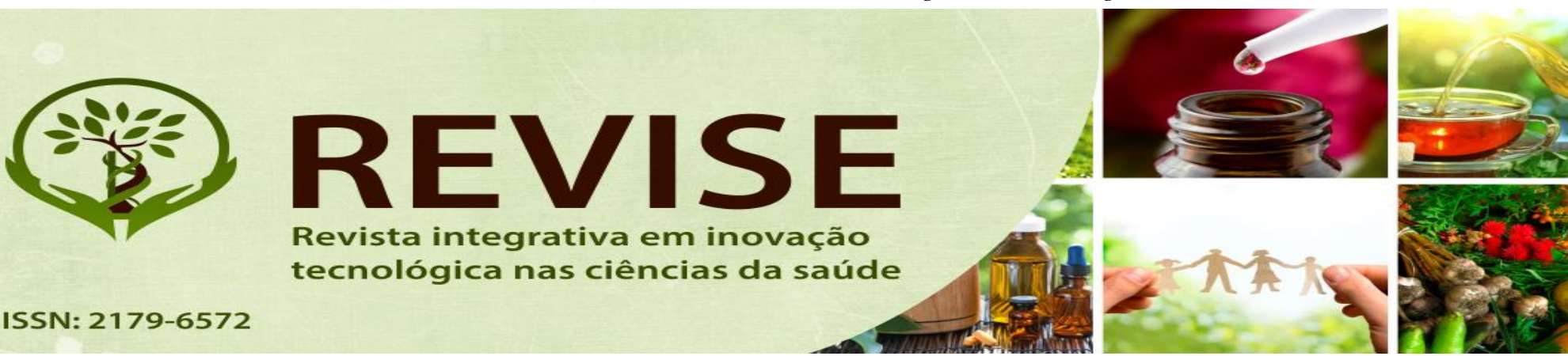

ISSN: $2179-6572$

Revista integrativa em inovação tecnológica nas ciências da saúde

Silva e Romano (2015) identificaram em sua pesquisa o acolhimento centrado no Agente Comunitário de Saúde (ACS) e pouco envolvimento de outros profissionais de nível superior da equipe, que respondiam apenas de forma pontual à demanda, com exceção do enfermeiro. Alves et al. (2014) em sua pesquisa concluiu que menos da metade dos profissionais (46,3\%) estão capacitados para realizar o acolhimento.

Como uma categoria temática que elucida a prática do acolhimento na ESF, Rocha e Spagnuolo (2015) apresentam o modelo assistencial biomédico, centrado na doença, como aspecto agravante para o acolhimento. Campos et al. (2014, p. 259) corroboram, ao afirmarem que "a relação usuário-profissional deveria estar baseada na mudança de paradigma, isto é, encampar os princípios da saúde coletiva, tendo como foco a saúde e não a doença". Lima et al. (2014), afirma ser uma questão desafiadora a relação entre profissionais de saúde e usuários, sugerindo ser algo essencial para a reorganização dos serviços de saúde pública.

\section{Sobrecarga de trabalho}

Rocha e Spagnuolo (2015) destacam ser um desafio na incorporação do acolhimento a exigência de produção, a imprevisibilidade na procura pelo atendimento, o imediatismo na resolução dos problemas e recursos humanos insuficientes. Este último fator afetando diretamente os primeiros.

Tesser e Normam (2014) corroboram com os achados de Rocha e Spagnuolo (2015), ao associarem o número de usuários inscritos por ESF ter bastante influência na prática do atendimento e na satisfação dos usuários e dos profissionais de saúde envolvidos, o que estaria intimamente ligada ao acesso e ao volume de trabalho da equipe. Ressaltam ainda que na tentativa de realização de acolher bem é comum gerar nos profissionais da equipe "angústia, carga extenuante de trabalho e estresse emocional". Sendo assim, afirmam a necessidade de ajustar o número de profissionais e diminuir o volume de usuários adscritos por equipe da Saúde da Família no intuito de viabilizar o acesso e o atendimento dos usuários alcançando a proposta da longitudinalidade. 

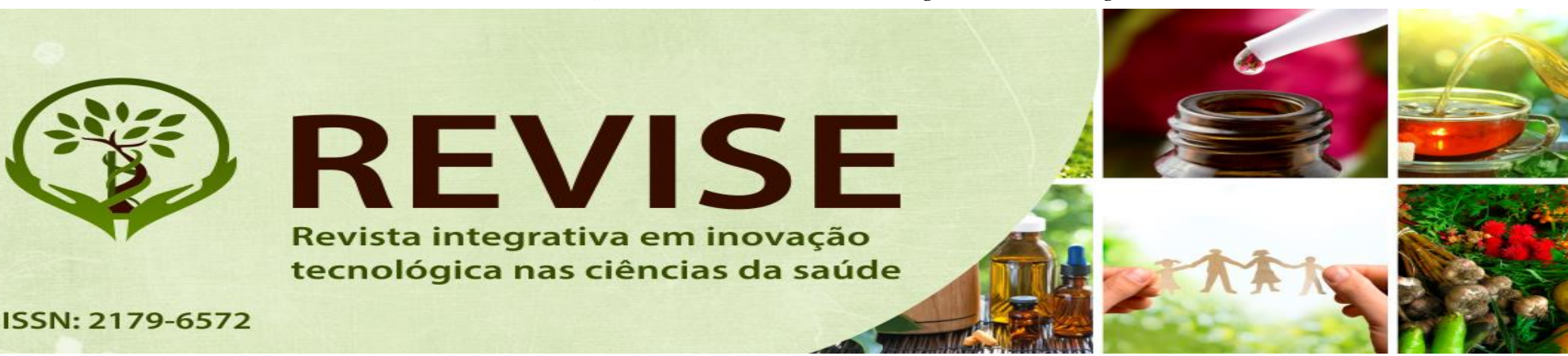

ISSN: $2179-6572$

Revista integrativa em inovação tecnológica nas ciências da saúde

Na pesquisa realizada por Silva e Romano (2015) em unidades básicas do município do Rio de Janeiro percebeu-se na prática que o Agente Comunitário de Saúde é o profissional que sofre maior sobrecarga de trabalho. Além das visitas domiciliares, estes acolhem os usuários na recepção, nos grupos de ações e ainda facilitam o acesso, funcionando como porta voz da comunidade, organizando a demanda dos usuários que buscam atendimento diariamente.

Brehmer e Verdi (2010 apud Coutinho; Barbieri e Santos, 2015), em sua pesquisa abordam que questões relacionadas à "(des) organização" da quantidade de profissionais, ao que indica refere-se à grande demanda para poucos profissionais, refletindo negativamente nos sujeitos envolvidos. Os usuários dos serviços de saúde não receberiam, portanto, atendimento adequado devido ao cansaço dos profissionais provocado pela sobrecarga de trabalho.

A jornada de trabalho excessiva, segundo Soratto et al. (2017), foi apontada como fator de insatisfação para os profissionais que atuam na ESF, pois, o tempo que é dedicado ao trabalho ocupa grande espaço na vida destes afetando a qualidade de vida pessoal e familiar, dando destaque para a questão de muitos deles terem duplo ou triplo vínculo de trabalho.

\section{Ambiência}

A inadequação da infraestrutura do ambiente para o acolhimento é tratado por Coutinho, Barbieri e Santos (2015) como obstáculo para a sua realização, ao afirmar que a ausência de condições essenciais para o recebimento dos usuários configura-se como uma violação das necessidades individuais.

Foi observada por Rocha e Spagnuolo (2015), a inexistência de um local destinado ao acolhimento, acontecendo assim em todos os espaços possíveis, seja no interior ou fora da unidade de saúde. Resultado similar foi verificado por Silva e Romano (2015), que perceberam em seu estudo que o acolhimento se dava na entrada das unidades estudadas, nos corredores e em salas específicas onde um profissional procedia a avaliação da necessidade do

Acolhimento. Revista Revise, vol 3, Dossiê Gestão em Saúde, p.56-70. 

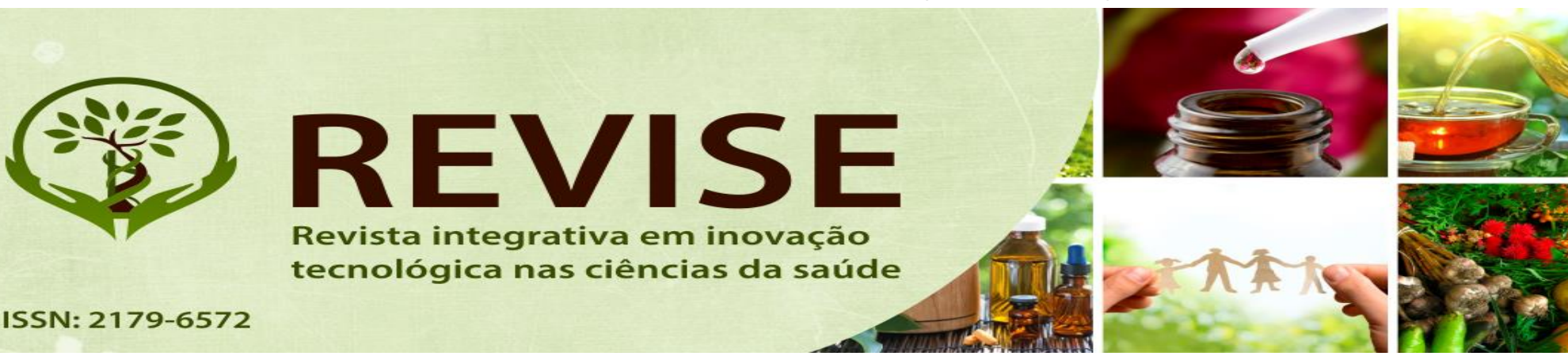

ISSN: 2179-6572

Revista integrativa em inovação tecnológica nas ciências da saúde

atendimento imediato ou não. Alves et al. (2014) analisaram o acesso às equipes certificadas pelo Programa Nacional de Melhoria de Acesso e da Qualidade da Atenção Básica (PMAQ$\mathrm{AB})$ e verificaram que menos da metade das equipes entrevistadas (36.6\%) referiram ter disponibilidade de sala específica para o acolhimento corroborando com o estudo de Rocha e Spagnuolo (2015).

Macedo et al. (2011 apud Silva e Romano, 2015) em sua concepção, afirmam que o acolhimento carente de um espaço físico "fragilizava o cuidado", vez que não permitia a construção de relação de confiança e compromisso dos usuários com os profissionais da equipe e os serviços. Um estudo realizado por Bezerra e Carvalho (2011, Apud Lopes (2015), sobre os profissionais de saúde e os dispositivos de mediação da APS, retrata que problemas estruturais podem dificultar as relações de troca, pois quando há falhas nas qualidades estruturais da unidade, ficam em risco a confiança e o respeito entre profissionais e usuários.

\section{Morosidade no Atendimento}

O tempo de espera por atendimento é um fator relevante a ser considerado no que diz respeito ao acolhimento. Coutinho, Barbieri e Santos (2015) ressaltam como um fator que merece atenção a questão da demora na marcação e resultado de exames, dificuldade de acesso a atendimento especializado, e as longas filas de espera, em consonância com o estudo de Tesser e Normam (2014), que identificou precariedade no acesso ao atendimento não urgente que leva o usuário a esperar várias semanas por assistência. Silva e Romano (2015), destacaram haver peregrinação dos usuários na busca por atendimento.

Campos et al. (2014) afirmam que as dificuldades para marcação de consultas e realização de determinados exames acabam gerando descrença no papel da APS, que em sua proposta tem a função de ser porta de entrada do SUS. Segundo os autores os usuários conselheiros municipais de saúde afirmam que as queixas que recebem estão relacionadas à morosidade em conseguir consulta com especialistas e realização de exames, que essa demora tem relação com a falta de profissionais, principalmente de médicos nas unidades de saúde. 

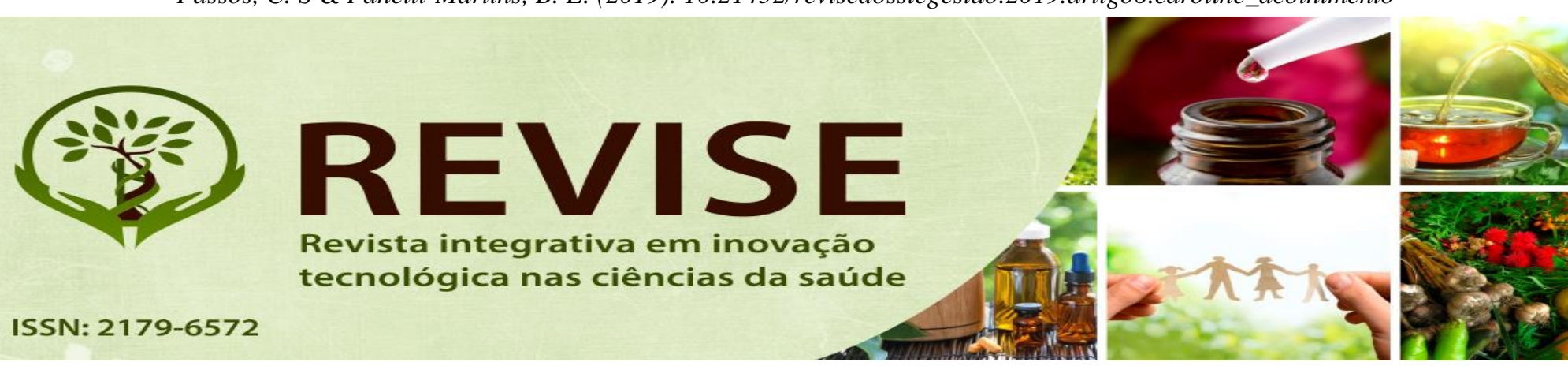

ISSN: 2179-6572

\section{Considerações Finais}

O estudo evidenciou questões relacionadas aos desafios do Acolhimento na APS. A prática do acolhimento vem sendo implementada no âmbito da ESF em todo o Brasil a fim de estabelecer a coordenação do cuidado, como proposto no modelo de organização de Redes de Atenção à Saúde, instituído no SUS, com vistas a operacionalizar os princípios da universalidade, integralidade, equidade e assim garantir a longitudinalidade no cuidado. Os desafios estão amplamente representados nos estudos sobre o tema e apontam inúmeras fragilidades que impossibilitam que de fato este acolhimento ocorra de forma satisfatória para todos.

A ineficácia no acolhimento está associada à sobrecarga de trabalho dos profissionais o que dificulta a realização de um acolhimento satisfatório, pois muitos desses profissionais enfrentam diariamente jornadas duplas ou triplas de trabalho, gerando cansaço físico e emocional. A ausência de local adequado para a realização do acolhimento expõe o usuário muitas vezes ao constrangimento de compartilhar com outros questões que dizem respeito apenas aos atores envolvidos no processo de saúde-doença. Tal situação pode gerar omissão de questões importantes relacionadas ao diálogo com o profissional de saúde, afetando diretamente os processos de comunicação e continuidade no cuidado.

A demora no atendimento para consultas na APS foi relatada com frequência pelos usuários, como motivo de insatisfação. A espera pelo atendimento é comum na busca do usuário pelo atendimento em saúde no Brasil. Além de gerar insatisfação, faz com que o usuário se sinta lesado com relação ao seu direto de acesso à saúde.

É no estabelecimento de vínculo, ou seja, nas relações éticas interpessoais e interprofissionais que está a força para mudanças, partindo da adoção emergencial de novos

Acolhimento. Revista Revise, vol 3, Dossiê Gestão em Saúde, p.56-70. 

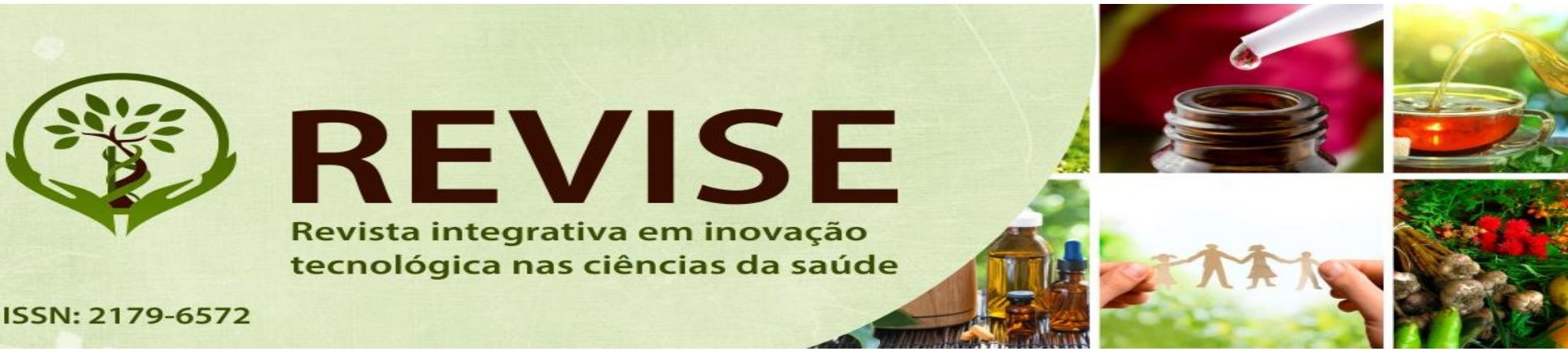

ISSN: 2179-6572

Revista integrativa em inovação tecnológica nas ciências da saúde

padrões de comportamento que possibilitem o acolhimento. É necessário, portanto, que estas fragilidades sejam sanadas, com o fortalecimento das ações propostas pelo modelo de assistência em saúde, e assim possibilitar a longituninalidade tão arraigada na proposta da ESF.

A política de acolhimento não deve funcionar somente como estabelecedora de diretrizes de organização de processo de trabalho na APS, mas sim como reorientadora, organizando a rede de serviços, no intuito de torná-la acolhedora, eficiente e resolutiva.

\section{Referências}

ALVES, Márcia Guimarães de Mello et al. Fatores condicionantes para o acesso às equipes da Estratégia Saúde da Família no Brasil. Saúde debate, Rio de Janeiro, v. 38, n. spe, p. 34-51, out. 2014.

ARANTES, Luciano José; SHIMIZU, Helena Eri; MERCHAN-HAMANN, Edgar. Contribuições e desafios da Estratégia Saúde da Família na Atenção Primária à Saúde no Brasil: revisão da literatura. Ciênc. saúde coletiva, Rio de Janeiro, v. 21, n. 5, p. 1499-1510, mai. 2016.

BARBOSA, Guilherme Correa et al. Política Nacional de Humanização e formação dos profissionais de saúde: revisão integrativa. Rev. bras. enferm., Brasília, v. 66, n. 1, p. 123127, fev. 2013.

BRASIL. Constituição. Constituição da República Federativa do Brasil. Planalto, 2014 Disponível <http://www.planalto.gov.br/ccivil_03/constituicao/constituicaocompilado.htm> . Acesso em: 15 dez. 2017.

BRASIL. Ministério da Saúde. HumanizaSUS: documento base para gestores e trabalhadores do SUS. 4. ed. Brasília, DF: Ministério da Saúde, 2010.

Campos, Rosana Teresa Onocko et al. Avaliação da qualidade do acesso na atenção primária de uma grande cidade brasileira na perspectiva dos usuários. Saúde em Debate, v. 38, n. Spe, Out. 2014.

COUTINHO, Larissa Rachel Palhares; BARBIERI, Ana Rita; SANTOS, Mara Lisiane de Moraes dos. Acolhimento na Atenção Primária à Saúde: revisão integrativa. Saúde debate, Rio de Janeiro, v. 39, n. 105, p. 514-524, Jun. 2015. 

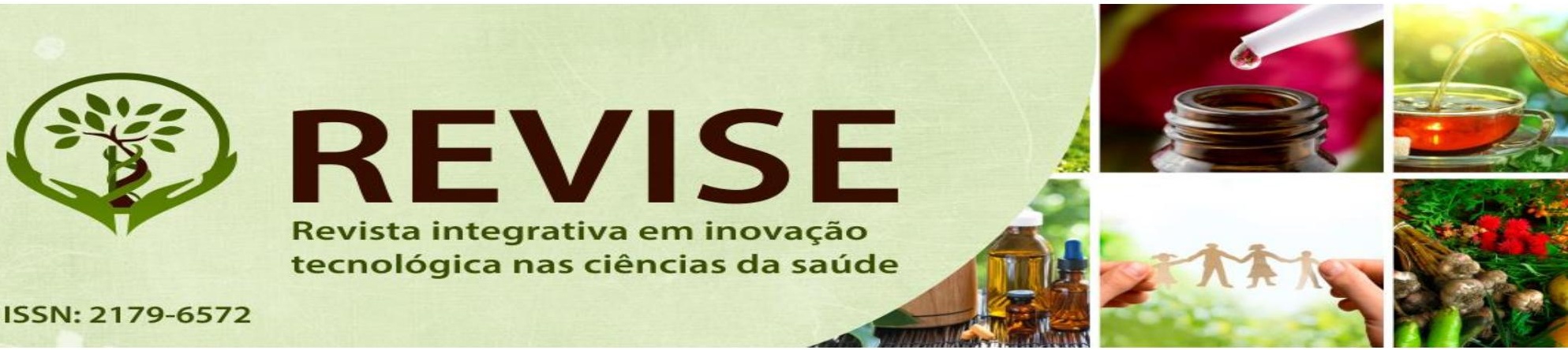

ISSN: 2179-6572

Revista integrativa em inovação tecnológica nas ciências da saúde

FARIAS, Anna Nunes Pereira Neta Humanização na Estratégia de Saúde da Família: Percepções dos profissionais que atuam em um Centro de Saúde da Comunidade na Cidade de Palmas - TO/ Palmas, 2017.

GARUZI M.; ACHITTI M.C.O.; SATO C. A.; ROCHA, S. A.; SPAGNUOLO R. S. Acolhimento na Estratégia Saúde da Família: revisão integrativa. Rev Panam Salud Publica. v. 35, n. 2, 144-149, 2014.

GIOVANI, Miriam Suzi Paro; VIEIRA, Camila Mugnai. Longitudinalidade do cuidado diante da rotatividade de profissionais na Estratégia Saúde da Família. Revista Eletrônica de Comunicação, Informação e Inovação em Saúde, [S.1.], v. 7, n. 4, dez. 2013.

LIMA, Cássio de Almeida et al. Relação profissional-usuário de saúde da família: perspectiva da bioética contratualista. Rev. Bioét., Brasília, v. 22, n. 1, p. 152-160, abr. 2014.

LOPES, Adriana Santos et al. O acolhimento na Atenção Básica em saúde: relações de reciprocidade entre trabalhadores e usuários. Saúde debate, Rio de Janeiro, v. 39, n. 104, p. 114-123, Mar. 2015.

ROCHA, Suelen Alves; SPAGNUOLO, Regina Stella. Acolhimento na visão complexa: ação coletiva emergente na Equipe de Saúde da Família. Saúde debate, Rio de Janeiro, v. 39, n. 104, p. 124-135, Mar. 2015.

SATO, Mariana e AYRES, José Ricardo de Carvalho Mesquita. Arte e humanização das práticas de saúde em uma Unidade Básica. Interface, Botucatu, vol.19, n.55, p. 1027-1038. Set. 2015.

SILVA, Tarciso Feijó da; ROMANO, Valéria Ferreira. Sobre o acolhimento: discurso e prática em Unidades Básicas de Saúde do município do Rio de Janeiro. Saúde debate, Rio de Janeiro, v. 39, n. 105, p. 363-374, jun. 2015.

SORATTO, Jacks et al. Insatisfação no Trabalho de Profissionais da Saúde na Estratégia Saúde da Família. Texto contexto - enferm., Florianópolis, v. 26, n. 3, 2017.

SORATTO, Jacks et al. Estratégia Saúde Da Família: Uma Inovação Tecnológica em Saúde. Texto Contexto Enferm. Florianópolis, v. 24, n. 2, p. 584-592, Abr-Jun. 2015.

TEDESCO, Janaina dos Reis; JUNGES, José Roque. Desafios da prática do acolhimento de surdos na atenção primária. Cad. Saúde Pública, Rio de Janeiro, v. 29, n. 8, p. 1685-1689, ago. 2013.

Acolhimento. Revista Revise, vol 3, Dossiê Gestão em Saúde, p.56-70. 

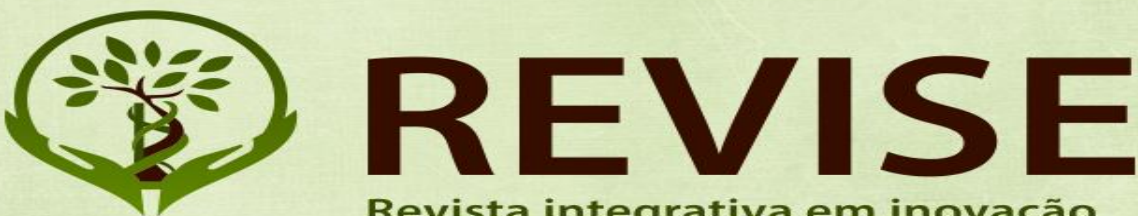

Revista integrativa em inovação tecnológica nas ciências da saúde

ISSN: $2179-6572$

TESSER, Charles Dalcanale; NORMAN, Armando Henrique. Repensando o acesso ao cuidado na Estratégia Saúde da Família. Saude soc. São Paulo, v. 23, n. 3, p. 869-883, Set. 2014. 